\title{
Inserindo a estratégia como prática no campo dos estudos organizacionais: uma proposta de método de aplicação a partir de um caso prático
}

\author{
Introducing the strategy as practice in the organization studies field: \\ a proposal application method from a practical case
}

Fabiano Oliveira da Silva ${ }^{[a]}$, Peter Bent Hansen ${ }^{[b]}$

[a] Mestrado em Administração e Negócios. Pontifícia Universidade Católica do Rio Grande do Sul, PUCRS, Brasil. Expresso Jundiaí Logística e Transporte LTDA. (SP). Executivo da área de logística empresarial, e-mail: fabiano@estrategiapratica.com.br

[b] Doutorado em Engenharia de Produção pela Universidade Federal do Rio Grande do Sul, UFRGS, Brasil. Professor da Pontifícia Universidade Católica do Rio Grande do Sul, Programa de Pós-Graduação em Administração - PPGAd, e-mail: peter.hansen@pucrs.br

\section{Resumo}

O atual cenário acadêmico no campo dos estudos em estratégia organizacional é povoado por diversas abordagens e correntes teóricas. Dentre estas, tem-se observado a emergência das abordagens que consideram aspectos sociológicos e subjetivos do "fazer estratégia", nos quais há destaque para a estratégia como prática. 0 presente artigo faz uma breve varredura nos postulados teóricos dessa abordagem e ilustra uma proposta de método de aplicação empírica deste corpo teórico, a partir de um estudo de caso realizado no ano de 2011 em uma empresa brasileira de grande porte. Como resultado, além da análise da estratégia em si da organização estudada, há a proposição de um método de aplicação da teoria no campo dos estudos organizacionais, adaptado da sistemática inicialmente formulada por Jarzabkowski.

Palavras-chave: Estratégia como prática. Método. Aplicação empírica. Análise estratégica.

\section{Abstract}

The current landscape in field of academic studies in organizational strategy is populated by different approaches and theoretical perspectives. Among these, we have observed the emergence of approaches that consider subjective and sociological aspects of "doing strategy", where there is emphasis on strategy as practice. This paper briefly scanning the theoretical postulates of this approach and illustrates a proposed method of empirical application of this body of theory from a case study conducted in 2011 in a large Brazilian company. As a result, besides the analysis of the strategy of the organization itself studied, there is a proposition 
of a method of application of theory in the field of organizational studies, adapted from the scheme originally formulated by Jarzabkowski.

Keywords: Strategy as practice. Method. Empirical application. Strategic analysis.

\section{Introdução}

O A fim de compreender as características e dinâmicas da estratégia organizacional, diversas são as abordagens e visões possíveis de se utilizar, com objetivo de realizar análises sobre as estratégias organizacionais. Porter (2004), por exemplo, afirma que uma organização precisa estar atenta às forças externas que atuam em determinado ambiente competitivo e com base nesta análise, a firma deve buscar uma posição estratégica que lhe seja a mais adequada, um posicionamento estratégico.

Henry Mintzberg (1987) propõe uma nova perspectiva acerca da análise das estratégias, afirmando que elas podem ser emergentes e não apenas deliberadas e planejadas. Em seguida, Mintzberg, Ahlstrand e Lampel (2000) identificam várias abordagens sobre estratégia organizacional e as agrupam em correntes ou escolas de três diferentes grupos: prescritivas, descritivas e um terceiro grupo, caracterizado como o de configuração. Além destas, outras visões sobre o que é a estratégia e como estudá-la também estão presentes no campo dos estudos organizacionais.

Diante da amplitude dos focos teóricos para os estudos de estratégia, Clegg, Carter e Komberger (2004) postulam a mudança na forma como a estratégia organizacional é estudada e trabalhada. Esses autores apresentam críticas à visão cartesiana da estratégia, que dissocia a formulação da implementação. Neste sentido, Whittington (2003), defende uma visão da estratégia que busca compreender como e onde a estratégia realmente acontece.

Whittington (2004a) também assinala que esta nova orientação na agenda de estudos e pesquisas sobre estratégia tem sido motivada pela instauração do paradigma pós-moderno, uma vez que a visão a partir do paradigma modernista acabou restringindo o olhar mais amplo e profundo da prática social da estratégia nas organizações. Assim, dentre as diversas abordagens estratégicas desenvolvidas no âmbito acadêmico e empresarial dos últimos 30 anos, uma que vem ganhando relevância e espaço cada vez maior no campo acadêmico é a estratégia como prática.
Sobre esta nova abordagem, Jarzabkowski e Whittington (2008) explicam que a estratégia como prática é um campo recente de pesquisa que traz ao centro das atenções a figura do gestor, e que essa visão tem crescido em resposta à sentida ausência dos atores estratégicos e suas atividades na maioria das pesquisas e dos artigos acadêmicos sobre estratégia, completando desta forma, uma lacuna existente nos estudos de estratégia.

Neste cenário, tem-se observado a crescente relevância e quantidade de estudos embasados na abordagem da estratégia como prática. Contudo, algumas questões decorrentes da emergência deste tema ainda são: como é possível aplicar a estratégia como prática empiricamente, em uma pesquisa de campo? E os resultados de pesquisa, como podem ajudar as organizações a melhorarem sua performance perante o ambiente competitivo?

Reunindo as considerações apresentadas, o presente artigo busca propor um método de análise da estratégia organizacional, utilizando a perspectiva da estratégia como prática para analisar o processo estratégico verificado nas organizações. Empiricamente, esta análise foi aplicada no ano de 2011 em uma empresa do transporte rodoviário de cargas brasileiro, e serviu como base para uma dissertação de mestrado, cujo enfoque foi centrado nas estratégias empregadas na organização estudada. A dissertação, de título "Análise estratégica de uma empresa do transporte rodoviário de cargas brasileiro: um estudo sob a perspectiva da estratégia como prática", foi submetida e aprovada junto à Pontifícia Universidade Católica do Rio Grande do Sul - PUCRS - em março de 2012.

Nesse trabalho, a principal contribuição foi a de oferecer uma aplicação empírica da abordagem, ao desenvolver uma pesquisa de campo com suas decorrentes análises e conclusões sobre o processo estratégico da empresa estudada, considerando a aplicação da estratégia como prática. No presente artigo, o enfoque está em apresentar e discutir o método de análise através do qual a pesquisa empírica foi viabilizada e a partir de quais bases teóricas 
a pesquisa e resultados obtidos foram alcançados. Além desse enfoque principal, este trabalho busca também avaliar a possibilidade de se aproveitarem os resultados de pesquisa em nível acadêmico, com objetivos corporativos, traduzidos em possíveis contribuições para o campo organizacional.

Desta forma, o texto está dividido, resumidamente, em três partes: primeiramente são apresentadas as ideias introdutórias, questão que norteou a pesquisa e objetivos do artigo. A segunda parte visa a compor uma breve revisão acerca do referencial teórico da estratégia como prática. $\mathrm{Na}$ terceira e última parte, é apresentado o método de pesquisa que foi aplicado em nível empírico, os resultados obtidos com a pesquisa original e as considerações finais deste trabalho.

\section{Revisão Conceitual}

Compreendendo um pouco da origem, questões e preceitos da estratégia como prática

O alicerce teórico desta pesquisa e da análise dos resultados foi a estratégia como prática (ou estratégia na prática). Esta abordagem sobre estratégia organizacional teve sua primeira "manifestação" no trabalho de Whittington (1996), quando esse autor propôs em seu artigo, que a estratégia, enquanto prática, levasse a sério o discurso e o trabalho dos próprios estrategistas. Assim, a estratégia como prática concentra-se no trabalho de "estrategização", sendo esse trabalho expresso em atividades como discursos, reuniões e análises nas quais a estratégia é verdadeiramente formulada e implementada.

Segundo Whittington (2004b), durante muitos anos os estudos sobre estratégia estiveram presos aos preceitos modernistas dos Estados Unidos dos anos 1960. Hoje, conforme afirma esse autor, as generalizações quantitativas e imparciais do modernismo, tornaram-se apenas uma das alternativas no campo da pesquisa sobre estratégia. 0 autor ainda explica que a estratégia é tradicionalmente interpretada como algo que as organizações possuem. A perspectiva da estratégia como prática foca a estratégia como algo que as pessoas fazem no dia a dia.

Assim, Jarzabkowski e Wilson (2002) elucidam que a estratégia como prática visa ao processo de interação dos gestores em relação a todo o processo da estratégia. Para esses autores, a estratégia envolve tanto inspiração (visão, formulação), quanto transpiração (meios pelos quais a estratégia é implementada).

Reafirmando os anseios por uma nova visão da estratégia, Whittington (2003) busca compreender como e onde a estratégia realmente acontece. Desta forma, propõe seis questões básicas acerca da estratégia, a saber:

1) Onde e como a atividade de criação e administração de estratégias realmente acontece?

2) Quem executa a atividade formal de criar e organizar as estratégias?

3) Quais são as habilidades necessárias a esta atividade e como elas são adquiridas?

4) Quais são as ferramentas comuns e as técnicas de criação e administração de estratégias? Como estas são utilizadas na prática?

5) Como é o trabalho de criar e organizar estratégias?

6) Como os resultados das estratégias são divulgados e utilizados? (WHITTINGTON, 2003, p.119).

Em relação aos atores estratégicos ou "quem" realiza as atividades estratégicas, Regnér (2003) expõe o fato de que a delimitação de como a estratégia realmente é feita e quem está envolvido em sua elaboração, também é importante para os gestores e para as empresas tentarem alcançar novos rumos em áreas estratégicas de crescimento.

Neste cenário, Johnson, Melin e Whittington (2003) assinalam que os gestores e futuros gestores estão se tornando mais exigentes em termos de suas expectativas sobre escolas de negócios. Suas frustrações são reconhecidas no crescente debate em torno da dissociação existente entre a investigação acadêmica e a prática organizacional.

Assim, a estratégia como prática surge, não como um "antídoto" a uma visão de estratégia organizacional, mas sim como um complemento, ou melhor, como uma nova "lente" para se analisar como de fato as estratégias acontecem dentro das organizações.

Para demonstrar esse pressuposto, Whittington (2004b) explica que a estratégia como prática não visa a contrapor outras abordagens estratégicas, tais como o modelo de Porter, as estratégias emergentes de Mintzberg, ou ainda outras ferramentas 
de gestão largamente difundidas no mundo corporativo, tais como o Balanced Scorecard.

Segundo Whittington (2004b), a estratégia como prática respeita o valor do planejamento estratégico tradicional, previamente formulado, desde que seja dispensada especial atenção às atividades cotidianas dos gestores ou microatividades, termo que os autores preferem utilizar, pois estas farão esse planejamento acontecer e permitir que os planos "saiam do papel". Se os gestores não tiverem habilidades para executar as microatividades estratégicas, o plano corre o risco de não acontecer.

Para Jarzabkowski (2003), a estratégia como prática visa a explicar como os atores da gestão realizam o trabalho da estratégia, tanto através de suas interações sociais com outros atores, como em função de práticas específicas presentes no contexto. Por tal razão esta abordagem tem profundo enfoque sociológico nas microatividades e interações dos gestores.
Inserindo a prática na análise organizacional

De acordo com as afirmações de Blackler (1993 apud JARZABKOWSKI, 2003), uma organização pode ser considerada um sistema de atividades que compreende três componentes principais: (i) os atores sociais (gestores), (ii) as estruturas organizacionais, coletivas e sociais (físicas, recursos, políticas, cultura, etc.) e (iii) as atividades práticas que os gestores exercem, conforme se ilustra na Figura 1.

Na Figura 1, Jarzabkowski (2003) aborda que segundo os resultados de pesquisa desse trabalho, o time de gestores, posicionados no topo do triângulo, foi identificado como "ator-chave" da estratégia como prática, pois estes gestores interagem continuamente com as estruturas organizacionais e coletivas, no lado esquerdo da Figura 1, envolvendo a cultura da organização, sua história e também, os outros "atores" que contribuem para a construção da atividade estratégica.

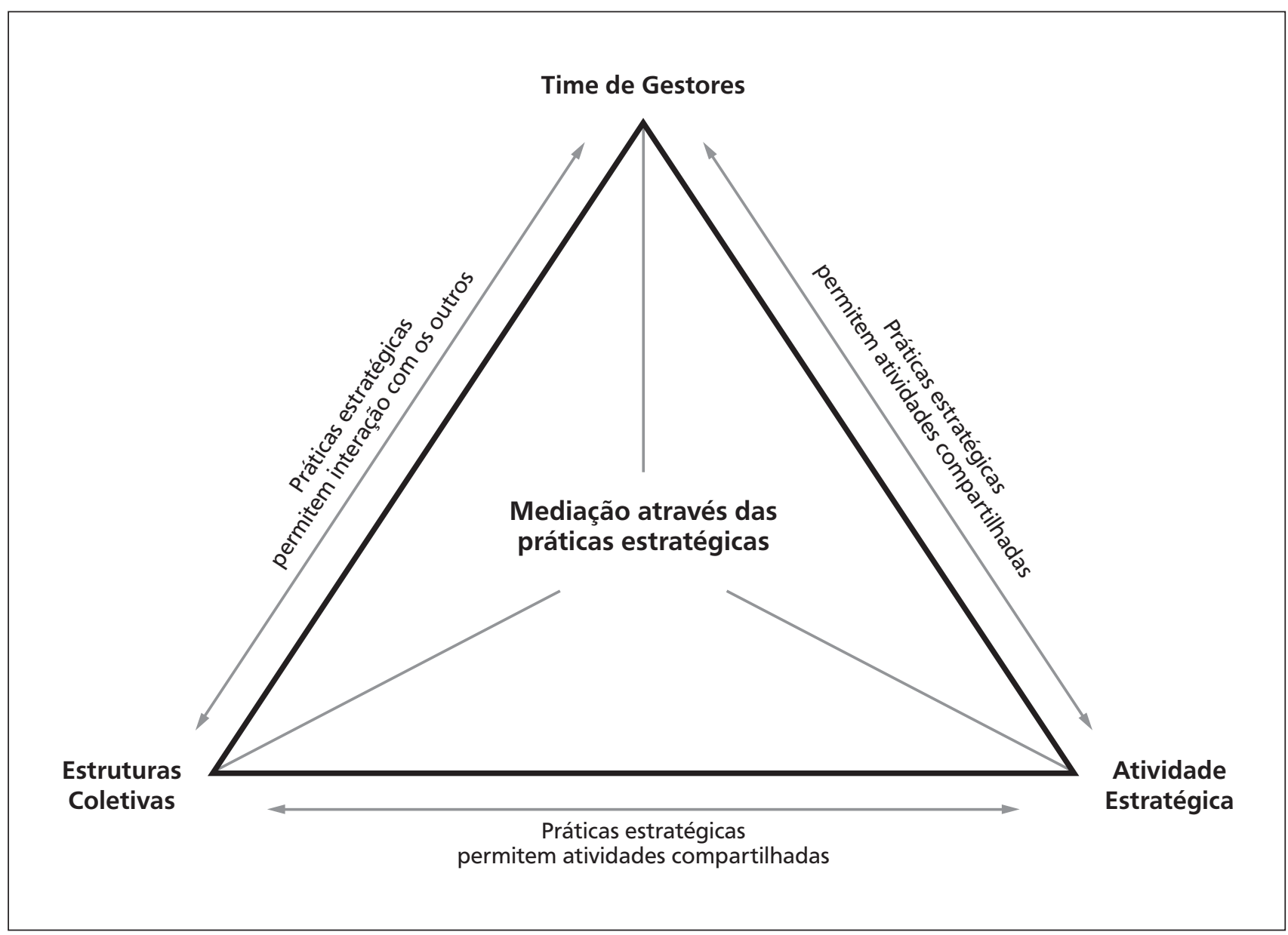

Figura 1 - O sistema de atividades no qual a estratégia como prática ocorre

Fonte: adaptado de Jarzabkowski (2003, p. 25). 
Outro ponto analisado por Jarzabkowski (2003) é a atividade prática, ilustrada como atividade estratégica, no lado direito do triângulo que representa o sistema de atividades. Esta atividade estratégica é resultante das interações entre os atores e as estruturas organizacionais ao longo do tempo e afetam toda a organização, na medida em que adquirem legitimidade entre os atores do sistema e também se tornam um componente importante do sistema de atividades.

Em seguida, há a contribuição da teoria da atividade, ao se interpretarem as práticas estratégicas, ao centro da Figura 1 que, segundo a autora, é através dessas práticas que ocorre a interação entre atores e as estruturas organizacionais. A autora ainda cita que a teoria da atividade sugere que essa interação ocorre com o emprego de técnicas e ferramentas, que os atores utilizam para interagir com seus ambientes. Desta forma o uso de tais ferramentas é prática, sendo orientada para construir a atividade (JARZABKOWSKI, 2003).

As ferramentas têm a finalidade prática de permitir que componentes organizacionais, tais como pessoas, recursos materiais e processos, realizem a atividade estratégica. No entanto, segundo Jarzabkowski (2003), a teoria da atividade não conceitua as ferramentas como um componente particular do sistema. Em vez disso, as ferramentas estratégicas são conceituadas como instrumentos de mediação entre as finalidades variadas e os interesses. Essas ferramentas de interação e mediação podem contribuir com as práticas através das quais a estratégia é construída.
Conforme Jarzabkowski (2003) são exemplos de ferramentas estratégicas, os instrumentos de coordenação e gestão dos recursos materiais da estratégia, bem como os meios pelos quais a estratégia acontece.

Ainda na Figura 1, Jarzabkowski (2003) explica que as setas são usadas para indicar as propriedades de práticas que permitem a interação estratégica e a atividade compartilhada entre os componentes, não necessariamente consensual, de um sistema de atividades. A fim de funcionar como um sistema, diferentes componentes da organização exigem um meio de interagir uns com os outros o suficiente para produzir uma ação estratégica.

Desta forma, se identificadas as práticas estratégicas e os procedimentos operacionais formais, é possível captar não apenas o modo formal, mas também as formas habitual e social de agir por meio do qual a estratégia é construída (JARZABKOWSKI, 2003).

\section{As práticas e as microatividades estratégicas}

Após estas análises com base na proposta de uma teoria da atividade, Wilson e Jarzabkowski (2004) abordam os níveis micro e macro da estratégia. Sobre estes níveis, argumentam que é importante relacionar qualquer análise no nível micro com influências e resultados em uma instância maior (unidade de análise macro), conforme se ilustra na Figura 2.

Nessa visão relacional, os níveis estratégicos macro e micro constituem dois polos de um contínuo que coexistem em uma tensão relacional.

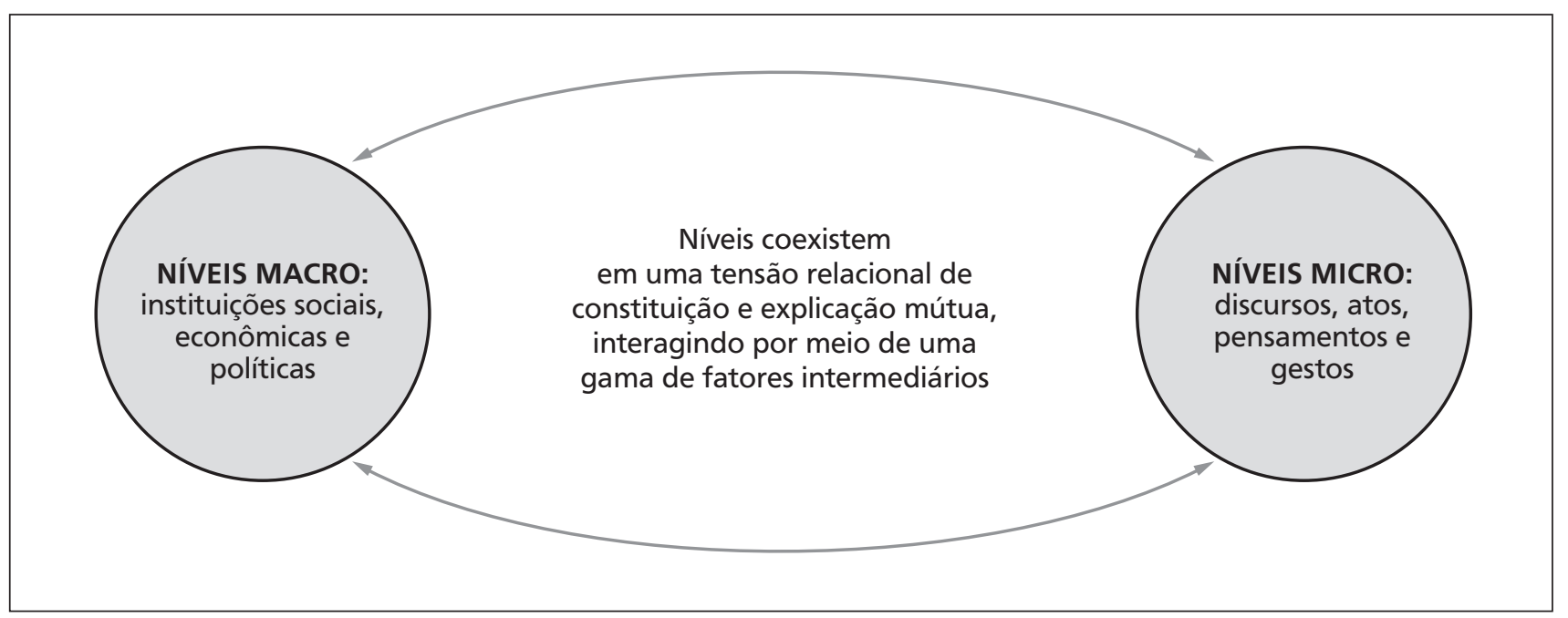

Figura 2 - Uma visão relacional de macro e micropráticas

Fonte: Wilson e Jarzabkowski (2004, p. 16). 
0 relacionamento entre esses dois polos é bidirecionado, de modo que qualquer atividade que ocorra esteja relacionada tanto ao contexto externo (macro), quanto ao intraorganizacional (micro). Assim as microatividades contribuem para a construção de contextos sociais mais amplos, mesmo sendo influenciadas por estes e assim ciclicamente, como exemplificam os autores:

Por exemplo, pode-se estudar o resultado de um determinado episódio de realização de estratégia ou o resultado de uma interação estratégica. Cada um deles pode ser moderadamente importante em si mesmo, mas, quando considerados como uma série de episódios e interações, eles afetam resultados mais amplos, como o desempenho das firmas. Uma questão fundamental para os estudiosos da estratégia é a construção de sólidas ligações nos relacionamentos entre microfenômenos e as questões mais macro que os circundam. Sugere-se que a visão relacional pode auxiliar orientando tais pesquisas (WILSON e JARZABKOWSKI, 2004, p.16).

Wilson e Jarzabkowski (2004) ainda complementam com os desafios de se definir o que constitui uma unidade de análise apropriada para estudar a prática ou a atividade. Segundo esses autores, conforme a natureza inter-relacionada dos fenômenos da prática pode ser difícil isolar os estudos em uma unidade de análise específica, como um "episódio de realização de estratégia" ou "conversas durante uma interação", já que outros dados participam deste processo de análise. Assim, os autores acima citados argumentam sobre a importância de se definir algum aspecto da prática e o que este aspecto deverá explicar para que se consiga ir além do mero empirismo.

Essas atividades localizadas de um grupo são o foco dos pesquisadores que veem tais comunidades como sistemas de atividades, em que o contexto do grupo fornece uma estrutura interpretativa para a criação de sentidos e para a ação (estratégica). Esses autores ainda assinalam que, em contrapartida, o situacionismo está localizado em um nível de análise muito mais macro. Repertórios e rotinas, assim como interações recursivas entre ação e contexto, são entendidos como demarcadores das micropráticas, sendo ao mesmo tempo influenciados por elas (WILSON e JARZABKOWSKI, 2004).

A partir destes pressupostos, Johnson, Melin e Whittington (2003) buscam maior amplitude para esta abordagem e propõem a adoção de uma visão baseada em atividades. Segundo os mesmos autores, há necessidade de articular os fenômenos "macro" com explicações "micro", exatamente o que pretende uma visão baseada em atividades.

Os autores ainda complementam que a visão baseada em atividades não nega a importância da pesquisa, para os gestores e pesquisadores, sobre as questões-macro. Esta é importante para que os estrategistas consigam alcançar e sustentar uma vantagem competitiva com base exclusiva em ativos ou competências organizacionais, em nível de gestão ou ainda, para diversificação e aquisição de empresas com sucesso (JOHNSON, MELIN e WHITTINGTON, 2003).

Neste sentido, Jarzabkowski $(2003 ; 2005)$, detalha como a perspectiva da estratégia como prática possui três focos principais, sendo estes: (i) a prática, (ii) os praticantes e (iii) as práticas. A prática (ou práxis) representa o próprio processo de fazer estratégia, entendendo-o como um fluxo das atividades organizacionais ou ainda, microatividades estratégicas. Os praticantes são as pessoas direta ou indiretamente envolvidas nessas atividades, habitualmente os gestores ou "estrategistas". Já as práticas dizem respeito aos instrumentos utilizados pelos atores, e que podem ser basicamente divididas em três tipos: primeiro são as práticas administrativas e racionais (tais como planejamento formal, orçamentos, indicadores de performance, etc.); em segundo as práticas discursivas, que compreendem os recursos cognitivos, linguísticos e simbólicos da interação estratégica (tais como materiais visuais, treinamentos e discursos) e; em terceiro, as práticas estratégicas que criam oportunidades de interação entre os praticantes (tais como reuniões, workshops e interação diária), os quais constituem os meios formais ou estruturados, através dos quais, a organização executa as estratégias.

Com base nos conceitos de práxis, práticas e praticantes abordados por Jarzabkowski (2003;2005), Whittington (2006) propõe um modelo de análise das atividades estratégicas. Este modelo está ilustrado a seguir na Figura 3 e possui estrutura diferente da Figura 1, proposta por Jarzabkowski (2003), tendo em vista que considera a existência de episódios de praxis estratégicas, bem como a consideração de vários estrategistas ou gestores, interagindo com diferentes práticas nestes episódios, como se pode observar. 


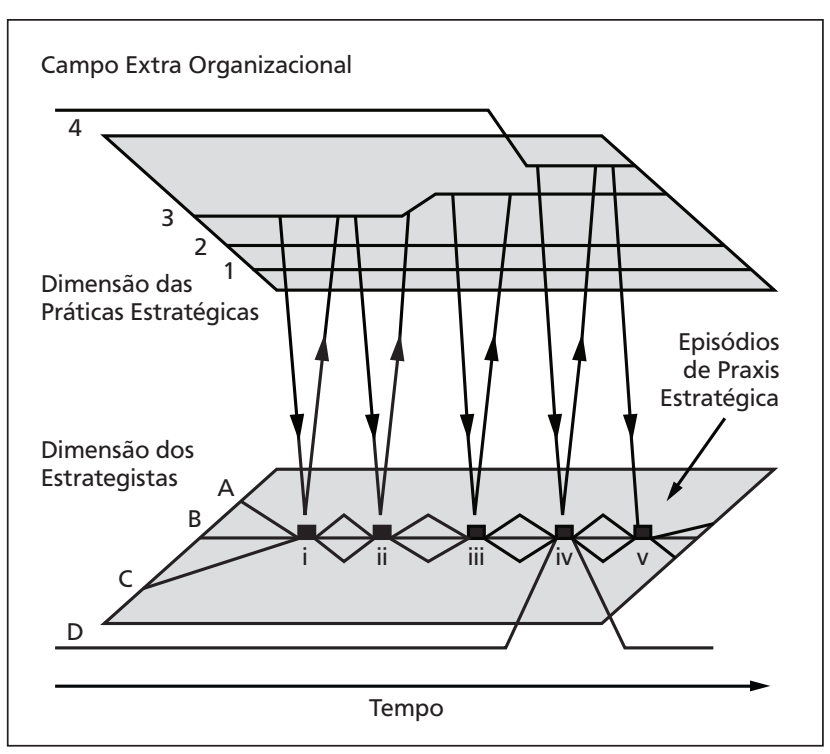

Figura 3 - Integração de práxis, práticas e praticantes

Fonte: adaptado de Whittington, 2006, p.621.

Na Figura 3, pode-se observar no paralelogramo inferior, os estrategistas A, B e C, tipicamente gestores de alta administração e o estrategista $\mathrm{D}$, que é externo à organização e faz parte do ambiente extra-organizacional, embora participe de determinados episódios de praxis estratégicas.

Segundo explica Whittington (2006), estes gestores interagem em diferentes episódios de praxis estratégicas internas à organização, que podem ser encontros formais ou informais, as quais estão numeradas de I até $\mathrm{V}$, também no paralelogramo inferior.

Enquanto executam as estratégias (nos episódios de praxis estratégicas), os praticantes moldam o conjunto de práticas disponíveis em seus contextos intra e extraorganizacionais. Estas práticas acabam se tornando legítimas para essa organização e estão ilustradas no paralelogramo superior, numeradas de 1 até 4 .

Whittington (2006) ainda explica que as práticas são possíveis rotinas e padrões gerados fora da organização, mas que foram imediatamente internalizados. Como exemplo, está a prática 4, que é externa e a partir do episódio IV, passa a fazer parte do conjunto de práticas da organização.

Entretanto, nenhuma dessas práticas é fixada na trajetória da organização ao longo do tempo. Conforme esses estrategistas moldam as práticas, eles reproduzem e, ocasionalmente, alteram o "estoque" de práticas disponíveis, para o próximo episódio de praxis estratégica. Isto porque na maioria das vezes, eles apenas reforçam essas práticas, repetindo-as e continuando a confiar nelas. Contudo, ocasionalmente, e talvez por improvisação ou necessidade de síntese, os gestores podem adaptar tais práticas, como o fazem com a prática 3 no segundo episódio de praxis (ii), na Figura 3, representada pela torção da linha da prática 3. Ocasionalmente, os gestores também podem aceitar uma nova prática a partir do exterior, como no quarto episódio de praxis, com a introdução da prática 4 .

Neste caso, a nova prática é levada para a organização por um ator extraorganizacional, o estrategista D - talvez um consultor de estratégia. Em seguida, a prática 4 é aceita como útil e legítima, consolidando-se como uma nova prática recorrente entre esse conjunto de praticantes, embora o gestor D não participe diretamente no episódio seguinte de praxis (WHITTINGTON, 2006, p.621).

\section{A proposta metodológica aplicada empiricamente}

Após a realização de um apanhado teórico acerca da estratégia como prática e sua abordagem sobre 0 que é estratégia, como esta ocorre e o que deve ser analisado nas organizações, buscou-se a composição de um framework preliminar de análise, acerca do referencial levantado sobre a estratégia como prática, 0 qual pode ser ilustrada pela Figura 4 a seguir.

0 objetivo do fluxo de análises verificado na Figura 4 é poder compreender, identificar e sistematizar, como o desempenho das microatividades por parte dos gestores no seu dia a dia fazendo uso de suas habilidades, interage com os as estruturas organizacionais, e as atividades estratégicas ou estratégias efetivas da organização.

Assim, este framework preliminar de análise, possui como base o modelo do sistema de atividades proposto por Jarzabkowski (2003) e ilustrado no presente trabalho através da Figura 1.

Nessa ilustração, Jarzabkowski (2003) estabelece uma relação direta e interativa entre esses fatores estratégicos, definindo o contexto da atividade prática como um sistema de atividades. Segundo a autora, uma organização pode ser considerada um sistema de atividades que compreende três componentes ou fatores: (i) os atores sociais (gestores e subordinados), (ii) as estruturas organizacionais (físicas, recursos, políticas, cultura, etc.) e (iii) as atividades práticas que os gestores exercem em suas rotinas. 


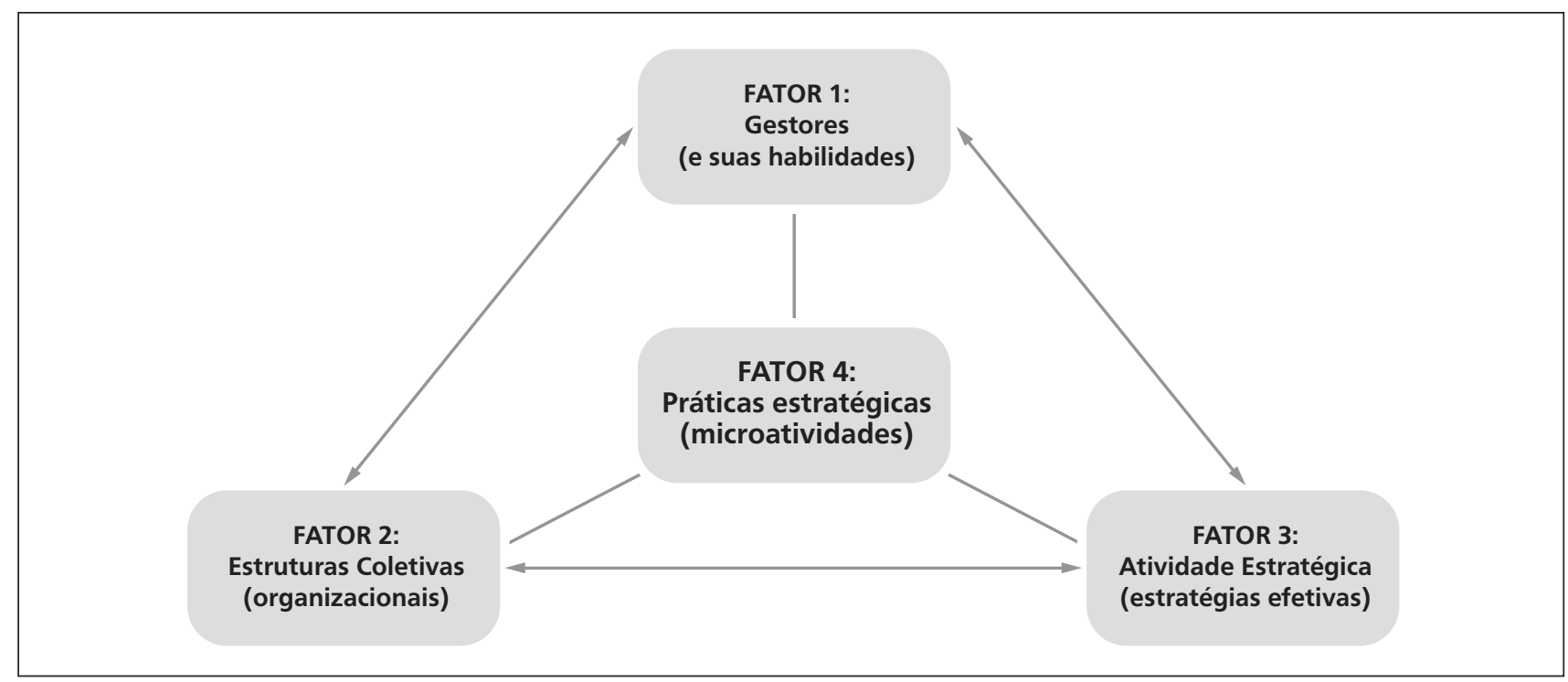

Figura 4 - Fluxo de análise da estratégia como prática

Fonte: os autores, 2012.

Neste modelo de análise, propõe-se a mesma base utilizada por Jarzabkowski (2003) em termos de "atores" da estratégia. Porém, nessa ilustração (Figura 4) os "atores" aparecem como fatores de análise. Além disso, nesse modelo agregam-se alguns conceitos e definições aprofundadas por Whittington (2006), no sentido de clarificar o que pode ou não ser interpretado como um fator do sistema de atividades.

Desta forma, a análise proposta pela figura 4, os fatores estratégicos a serem considerados são os mesmos do sistema de atividades descrito por Jarzabkowski (2003) e servem de base para análise dos resultados da presente pesquisa, agregando-se apenas a explicação pormenorizada de cada um destes, na medida em que se pode complementar com as afirmações de outros autores, conforme segue.

- Fator 1: são os Gestores, praticantes, estrategistas, as pessoas que executam as atividades estratégicas, podendo ser proprietários, diretores ou funcionários em nível de gestão (WHITTINGTON, 2006), dispondo de suas habilidades (consideravelmente indissociáveis). Conforme Jarzabkowski (2005), o "fazer estratégia por parte dos gestores, depende da habilidade astuciosa para usar, adaptar e manipular os recursos que são empregados para se engajar na formação da atividade da estratégia ao longo do tempo" (JARZABKOWSKI, 2005, p. 34).
- Fator 2: são as Estruturas coletivas ou organizacionais, é o aparato tangível ou intangível que molda o contexto no qual os gestores atuam. Jarzabkowski (2003) cita como exemplos a cultura da organização, sua história e "outros atores", os quais se podem entender como outros fatores contextuais ao acontecimento da atividade estratégica. Para efeito de análise da pesquisa realizada, utilizou-se o termo estruturas organizacionais, entendendo que estas podem ser, também, coletivas, bem como apresentarem-se em formas intangíveis ou tangíveis.

- Fator 3: Atividade estratégica, que Jarzabkowski (2003) explica ser o resultado das interações entre os atores e as estruturas coletivas e organizacionais ao longo do tempo e que afetam toda a organização. Esse fator, Whittington (2006) aprofunda a caracterização, afirmando serem conjuntos de tecnologias, rotinas, ferramentas, conceitos, ideias e procedimentos para pensar e agir que os estrategistas usam para executar a estratégia, legitimando-as através de normas ou de experiências passadas. Assim, esses conceitos ligam-se ao que se prefere chamar de "estratégia(s) efetiva(s)", pois representam padrões de ações estratégicas ou meios para atingir aos objetivos, que o sistema de atividades já possui e usa na execução das atividades.

- Fator 4: Práticas estratégicas: são as práticas cotidianas dos gestores, também encontradas em 
certas publicações referidas com o termo "praxis". Jarzabkowski (2003) afirma que é através destas práticas que ocorre a interação entre atores e as estruturas organizacionais. Whittington (2006) ainda explica que a "praxis" é o trabalho de fato realizado pelos gestores, ao se executar a estratégia. Como exemplo, o autor cita que estas podem ser reuniões, projetos, conversas, etc. Esta caracterização, liga-se ao que Johnson, Melin e Whittington (2003) chamam de microatividades, quando afirmam que se precisa de grande quantidade delas para se compor a estratégia e o processo de fazer estratégia na prática. Com isto, o centro da análise proposta pelo framework preliminar, são as microatividades da organização estudada.

Além dos fatores listados, há também outro ponto de convergência entre o sistema de atividades proposto por Jarzabkowski (2003) e o modelo de análise proposto na pesquisa empírica realizada. Trata-se das setas, conforme se pode observar nas Figuras 1 e 4. Contudo, na Figura 1, as setas servem para demonstrar as propriedades das práticas das interações e atividades estratégicas compartilhadas (JARZABKOWSKI, 2003). Na Figura 4, as setas são utilizadas para ilustrar o fluxo interativo entre os fatores do sistema e as relações existentes entre estes.

Enfim, foi com base nesta proposta de framework, baseado no sistema de atividades adotado por Jarzabkowski (2003), complementado pelas contribuições dos demais autores já mencionados, que a análise empírica foi realizada. A partir desta referência, é que se realizaram análises pormenorizadas e a montagem de um novo framework de análise, o qual exprime os resultados de pesquisa de campo, conforme se pode visualizar na Figura 5 do presente trabalho.

Em complemento, julga-se importante contextualizar que a pesquisa empírica realizada no ano de 2011 desenvolveu-se em conformidade com as indicações dos pesquisadores da estratégia como prática. Estas podem ser exemplificadas como a contribuição de Rasche e Chia (2009), autores que afirmam que os estudiosos de estratégia como prática, tem que dispensar mais atenção aos métodos de pesquisa que reconheçam a contextualização das práticas de estratégia e precisam obter familiaridade com as práticas de estratégia. Aproximar-se das práticas de estratégia rotineiras significa viver entre os estrategistas, a aprendizagem de sua linguagem, tendências e disposições, participando de suas práticas e rituais (RASCHE e CHIA, 2009).

Desta forma, a pesquisa realizada teve caráter exploratório e qualitativo, delineada sob a forma de um estudo de caso. Sobre a sua temporalidade, a pesquisa foi do tipo corte transversal. Quanto às técnicas utilizadas para a coleta de dados, estas foram as seguintes:

- Análise de documentos, arquivos e dados secundários da organização estudada, com objetivo de identificar possíveis estratégias efetivas da organização, em diferentes tipos de documentos pesquisados, tais como livro histórico da empresa, vídeo institucional, impresso publicitário, relatório de performance, etc. Estas possíveis estratégias foram identificadas através de evidências empíricas, devidamente registradas através de um roteiro de análise documental.

- Observação não participante dos gestores estudados, visando a capturar as nuances corporais, de fala e as interações entre estes, além das estruturas organizacionais com as quais os gestores possuem contato em seu dia a dia.

- Entrevistas em profundidade e semiestruturadas com os gestores estudados; com estas, buscou-se pesquisar atributos como interpretações do ambiente organizacional, decisões, relações com estratégias efetivas da organização e a participação dos gestores entrevistados em decisões da organização.

No tocante ao grupo de gestores pesquisados, este foi definido de maneira não probabilística, na qual foram selecionados treze gestores nos três níveis de lideranças da empresa, à saber: diretivo, gerencial e supervisão, com o objetivo de conseguir resultados de pesquisa que expressassem como, de fato, as microatividades estratégicas ocorrem na organização. Desta forma procurou-se um alinhamento com os estudos de caso realizados por Jarzabkowski e Wilson (2002) e Jarzabkowski (2003), guardadas as diferenças existentes entre as organizações pesquisadas por esses autores e a organização selecionada para a pesquisa empírica em questão. Além disso, todos os gestores selecionados e convidados a participar, possuíam contato com as estratégias da organização, seja em nível de formulação, planejamento, seja na implementação diária destas. 
Assim, na primeira etapa da coleta de dados, através da análise documental, foi levantado e analisado um conjunto de seis documentos de grande relevância para a organização. Em seguida, na segunda etapa, houve observações não participantes em reuniões com o envolvimento dos treze gestores selecionados e ainda, observação dos mesmos em seus ambientes profissionais, com objetivo de capturar informações e percepções referentes às microatividades desenvolvidas pelos gestores, suas habilidades pessoais e também, as estruturas organizacionais com as quais os mesmos mantêm contato diário. Na terceira e última etapa da pesquisa na empresa estudada, houve aplicação de entrevistas semiestruturadas com o mesmo grupo de treze profissionais com funções de liderança.

Levantados os dados sobre a empresa analisada, foi realizada a análise de conteúdo em profundidade destes, aplicando-se a técnica de triangulação de dados, a fim de conferir maior rigor científico e buscar consistência nos resultados de pesquisa.

A triangulação de dados ocorreu a partir do confronto de resultados obtidos nas duas primeiras técnicas (análise documental e observação não participante) com os resultados das entrevistas semiestruturadas, a fim de realizar a análise dos resultados e capturar possíveis confirmações dos resultados obtidos das duas primeiras técnicas, por parte da terceira técnica de coleta. Isto porque, as duas primeiras técnicas de coletas de dados empregadas, são baseadas em percepções e interpretações do pesquisador. A terceira técnica de coleta de dados, no entanto, é baseada nas percepções e concepções dos respondentes, neste caso os gestores, considerados os "atores principais" do embasamento teórico utilizado na pesquisa - a estratégia como prática. Por este motivo, a técnica de entrevistas semiestruturadas foi utilizada com caráter confirmatório dos resultados das duas anteriores.

Feitas as análises e cruzamentos, foi possível alcançar os resultados de pesquisa, os quais serão apresentados no próximo tópico deste artigo.

\section{Análise dos resultados obtidos na aplicação do método proposto}

A análise e interpretação dos dados coletados através do modelo analítico selecionado pela aplicação das três técnicas de coleta dados, conforme foi apresentado no tópico anterior, permitiu aos pesquisadores a construção de inferências lógicas de relações existentes entre os resultados da pesquisa que foi realizada sob este modelo.

A primeira relação que foi possível identificar é a de intenso relacionamento entre os gestores e as estruturas organizacionais, sobretudo os recursos tangíveis e intangíveis disponibilizados pela empresa. A relação entre os gestores e as estruturas é tão intensa, que no processo investigatório não foi possível dissociar de maneira clara e objetiva a atuação isolada dos gestores ou destes recursos, no desempenho de uma microatividade estratégica em detrimento de outra, ou ainda, que um recurso (tangível ou intangível) isoladamente, favorece mais uma estratégia efetiva do que outra.

Outra verificação, foi de que os recursos e outras estruturas materiais da organização não alcançam, de maneira isolada, relevância dentro do contexto organizacional, a ponto de permitir a constatação de que um recurso pode sustentar uma estratégia efetiva da organização. Constatou-se também, que recursos tangíveis e intangíveis não substituem a ação de um gestor, no sentido de produzir microatividades que sustentem ou contribuam para a sustentação de uma estratégia efetiva da organização.

Além disso, os recursos, principalmente os tangíveis, observaram-se relativamente inertes, talvez pela sua natureza física e material, obviamente. Toda a movimentação e desempenho de ações, identificadas como microatividades estratégicas, foram realizadas pelos gestores. É como se estes dessem "vida" às microatividades e às estruturas organizacionais, emprestando-lhes a forma como estas se apresentam ou possibilitando a sua ocorrência.

Assim, a análise e interpretação dos dados de pesquisa permitiram clarividência do fato de que os gestores se utilizam de suas habilidades e competências, cercam-se de estruturas organizacionais, como ferramentas, a fim de apoiar e buscar o intento de produzir atividades que acabam, por fim, sustentando estratégias efetivas da organização.

Esta constatação é coerente em relação ao que defendem os autores da estratégia como prática, podendo-se citar principalmente Jarzabkowski e Wilson (2002) e Jarzabkowski (2003), tendo este segundo trabalho emprestado o seu modelo de análise, conforme se pode visualizar na Figura 3, e também contribuído de forma significativa para o modelo proposto nesta pesquisa, conforme consta na Figura 4, ambas neste artigo. Contudo, é importante nesta etapa da análise lembrar que o famework de análise 
proposto na Figura 4 foi aplicado e desenvolvido durante o processo de pesquisa e análises empíricas, possibilitando a montagem de um novo framework, desta vez representando as conclusões analíticas da pesquisa (Figura 5 a seguir).

Desta forma, no framework teórico-empírico aqui desenvolvido como resultado da pesquisa de campo, os gestores e as estruturas organizacionais podem ser alocadas no mesmo grupo de fatores, pois interagem com as estratégias efetivas da organização através das microatividades, como se pode observar na Figura 5 que segue.

Outra característica da interação dos gestores e das estruturas organizacionais com as estratégias, é que esta ocorre principalmente através das microatividades dos gestores, ou seja, as atividades cotidianas dos gestores observados, são permeadas por ações estratégicas, que se manifestam na forma de estratégias efetivas e assim foram identificadas e registradas durante o processo de pesquisa.

Como se pode observar na Figura 5, têm-se os gestores e as estruturas organizacionais polarizados (ao lado esquerdo da figura) como o fator ativo das estratégias organizacionais, ilustrados através de um diagrama radial, no qual os gestores, com suas habilidades e competências em executar as microatividades estratégicas são o núcleo desse polo. Já as estruturas organizacionais, basicamente representadas por recursos da empresa, funcionam como ferramentas ou forças agregadas aos gestores, para que possam desempenhar as referidas microatividades (disposição periférica ao círculo que simboliza os gestores, em círculos menores).

Em seguida, a Figura 5 ilustra no outro polo (lado direito da figura), as estratégias efetivas da organização, que foram possíveis de se registrar como resultado da pesquisa. Por questões de confidencialidade em relação à organização estudada, o presente trabalho não pormenoriza a explicação desses grupos de estratégias identificadas, bem como não detalha cada microatividade ou ainda dos recursos e habilidades de que os gestores dispunham quando da realização da pesquisa.

\section{Considerações finais}

Pesquisar sobre a rotina diária de gestores para identificar o que estes realmente fazem, como interagem com certas estruturas organizacionais e com as estratégias, não é tarefa fácil. Para responder às dificuldades deste tipo de pesquisa de campo, somente o uso de métodos flexíveis, adaptativos e capazes de reduzir as dificuldades em se obter o dado desejado, no momento certo.

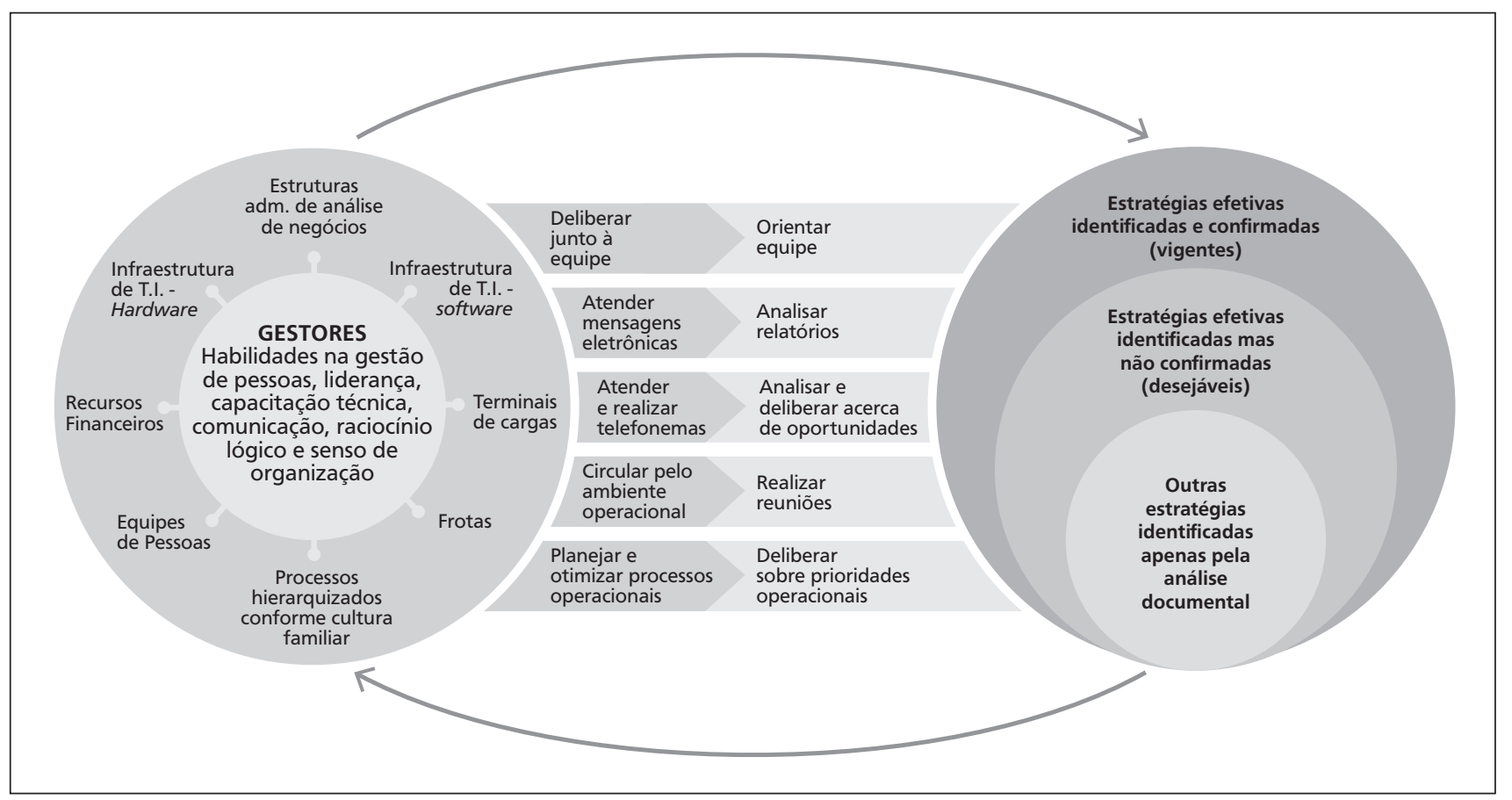

Figura 4 - Análise estratégica da empresa pesquisada, sob a perspectiva teórica da estratégia como prática Fonte: os autores, 2012. 
Neste sentido, a pesquisa qualitativo-interpretativa demonstrou-se eficaz, pois permite ao pesquisador buscar diferentes técnicas de coleta de dados, como meio de suprir a análise dos resultados com rigor científico, sem, no entanto, prender-se em técnicas tipicamente quantitativas. É preciso ainda, considerar que estes resultados são formados por vários atributos subjetivos e, em várias situações, comportamentos de pessoas, interpretações de normas e políticas informais do grupo pesquisado, etc. Não obstante, o formato de pesquisa, com delineamento de estudo de caso único, também cumpriu o seu objetivo, pois foi possível, com base em dados coletados através de três diferentes técnicas, chegar-se a um framework de análise baseado na teoria (vide Figura 4), e que permitiu obterem-se conclusões sobre o caso analisado (vide Figura 5). Embora os resultados em si não possam ser replicados, julga-se possível a replicação deste tipo de pesquisa e modelo de análise, com o objetivo de verificarem-se os resultados de outros casos em outras organizações e, possivelmente, traçar-se um comparativo entre os resultados entre uma e outra organização, sobretudo no que tange às microatividades e estratégias efetivas, a fim de se confrontar semelhanças e diferenças, buscar padrões e conclusões comparativas.

Assim, a primeira consideração que se pode fazer sobre o modelo metodológico utilizado, é que este serviu ao seu objetivo naquela pesquisa, pois mostrou-se capaz de capturar nuances sutis e subjetivas dos gestores, à frente de suas microatividades, no momento em que estes interagem com as estruturas organizacionais e "realizam as estratégias", conforme observa-se na Figura 5.

No que tange à teoria que foi utilizada como pano de fundo, a estratégia como prática, pode-se constatar que a teoria verificou-se flexível, pois concentra-se nas atividades diárias e cotidianas dos gestores, sem contrapor ou desprezar tudo o que já foi construído anteriormente acerca dos estudos em estratégia. Além disso, a teoria verificou-se consistente, uma vez que se baseia em atividades e características reais das organizações e seus gestores e não em características ideais, desejáveis ou irreais.

Desta forma, a análise baseada no arcabouço teórico da estratégia como prática pode ser capaz de analisar o acontecimento das estratégias, na sua forma pura e real, pois cada ação de um gestor, cada microatividade que este executa, pode conter um pouco da estratégia da organização. A partir desse pressuposto, pode-se, considerar que a estratégia como prática viu-se capaz de identificar e descrever as estratégias efetivas da organização estudada, mesmo que algumas estratégias identificadas nesta empresa não sejam formalizadas.

Com base nestas considerações, é possível concordar com Jarzabkowski e Whittington (2008), no sentido de que a estratégia como prática surge para preencher uma lacuna, que segundo esses autores, estava em aberto, pois as abordagens até então existentes, não valorizaram sobremaneira o "estrategista" a ponto de buscar compreender (e possivelmente aprimorar) as suas habilidades enquanto gestor e estrategista, para assim, desempenhar com maior eficácia as microatividades estratégicas.

As limitações da estratégia como prática são, primeiramente, aquelas inerentes a qualquer corpo teórico recente e ainda em formação. A busca por referencial, sobretudo em aplicações de pesquisas empíricas, ainda é um trabalho bastante árduo, pois as bibliografias baseadas em pesquisas, são bastante escassas. Em segundo lugar, a literatura sobre a estratégia como prática visa a explicar o que é a teoria em si e explica de maneira pormenorizada o embasamento teórico e a necessidade de se valorizar o estrategista, seu trabalho e suas habilidades.

Diante destas demandas, neste trabalho buscou-se a possibilidade e a construção de um método de se "experimentar" uma teoria nova, ainda em fase de construção, aplicando-se esta no campo empresarial, a fim de analisar e interpretar os fenômenos que dali emergem como resultados de pesquisa, a partir de um modelo teórico-empírico adaptado de uma relevante autora do tema e, a partir dos resultados de pesquisa, viabilizar análises sobre as relações entre os elementos da estratégia das organizações que possam contribuir para os interesses destas.

Por fim, neste trabalho foi possibilitada a estruturação de etapas para aplicação empírica deste novo corpo teórico, ainda em formação e cujo método de pesquisa (empírica) ainda não possui sugestões ou delimitações concretas. Talvez esta seja a principal contribuição que este artigo pode oferecer à academia, pois a pesquisa realizada poderá servir de base ou mesmo possibilitar desdobramentos posteriores para outros trabalhos científicos com a mesma abordagem teórica. 


\section{Referências}

CLEGG, S.; CARTER, C.; KOMBERGER, M. A “máquina estratégica": fundamentos epistemológicos e desenvolvimentos em curso. Revista de Administração de empresas, São Paulo, v. 44, n. 4, p. 21-31, 2004.

JARZABKOWSKI, P.; WILSON, D. C. Top teams and strategy in a UK university. Journal of Management Studies, v. 39, n. 3, p. 357-383, 2002.

JARZABKOWSKI, P. Strategic Practices: An Activity Theory Perspective on Continuity and Change. Journal of Management Studies, V.40, n.1, p. 23-55, 2003.

JARZABKOWSKI, P. Strategy as practice: an activity-based approach. London: Sage publications, 2005. Disponível em: <books.google.com.br>. Acesso em: 12 maio 2011.

JARZABKOWSKI, P.; WHITTINGTON, R. A Strategy-asPractice Approach to Strategy Research and Education. Journal of Management Inquiry, v. 17, n. 4, p. 282-286, 2008.

JOHNSON, G.; MELIN, L.; WHITTINGTON, R. Micro strategy and strategizing: towards an activity-based view? Journal of Management Studies, v. 40, n. 1, p. 3-22, 2003.

MINTZBERG, Henry. The Strategy Concept I: Five P's for Strategy. California Management Review, Fall, 1987.

MINTZBERG, Henry; AHLSTRAND, Bruce; LAMPEL, Joseph. Safári de estratégia: um roteiro pela selva do planejamento estratégico. - Porto Alegre: Bookman, 2000.

PORTER, M. Estratégia competitiva: técnicas para análise da indústria de da concorrência. 3. ed. Rio de Janeiro: Elsevier, 2004. 3aㅡ reimpressão.

RASCHE, Andreas; CHIA, Robert. Researching Strategy Practices: A Genealogical Social Theory Perspective. Organization Studies. v. 30, n. 7, p. 713-734, 2009.
REGNÉR, P. Strategy Creation in the Periphery: Inductive Versus Deductive Strategy Making. Journal of Management Studies, v. 40, n. 1, p. 57-82, 2003.

WILSON, D. C; JARZABKOWSKI P. Pensando e agindo estrategicamente: novos desafios para a análise estratégica. Revista de Administração de empresas, São Paulo, v.44, n.4, p.11-20, 2004.

WHiTTINGTON, R. Strategy as practice. Long R. Planning. v.29, n.5, p.731-735, 1996.

WHITTINGTON, R. The work of strategizing and organizing: for a practice perspective. Strategic Organization, v. 1, n. 1, p. 117-126, 2003.

WHITTINGTON, R. Estratégia após o modernismo: recuperando a prática. Revista de administração de empresas, São Paulo, v. 44, n. 4, p. 44-53, 2004a.

WhitTington, R. A prática da estratégia [7 dez. 2003]. Entrevistador: Marcelo Binder. São Paulo: Revista de Administração de Empresas - RAE, p. 39-43, 2004b.

WHITTINGTON, R. Completing the practice turn in strategy research. Organization Studies, vol. 27, n. $\stackrel{0}{5}$, pp. 613634, 2006.

Recebido: 10/08/2012

Received: 08/10/2012

Aprovado: 08/11/2012

Approved: 11/08/2012 
